\title{
ASSESSMENT OF WIND ENERGY POTENTIAL AND THE APPLICATION FOR MICRO-TURBINES
}

\author{
Jose Galarza \\ Department of Electrical and Electronic Engineering, \\ National University of the Center of Peru, \\ Huancayo 12006, Junin, Peru
}

\begin{abstract}
The use of renewable energies, mainly wind and photovoltaic, are sources of generation that have spread worldwide by micro-grids. In places where the implementation of electric grids is inaccessible or economically not feasible, the installation of wind micro-turbines and photovoltaic systems for electricity generation and water pumping systems has been implemented; however, renewable energies have not yet been used in some rural areas due to the lack of studies and initiatives of their own. In the present study, in situ measurements have been used to evaluate the wind potential in rural town and the application for micro-turbine. Through the Weibull Distribution, an analysis of the wind energy potential available in the area has been carried out incorporating commercial wind micro-turbines and energy cost analysis. The favorable wind levels and the nominal speed values of commercial turbines have allowed obtaining the capacity factor values and energy costs, which allowed determining the feasibility of the installation of wind micro-turbines to provide electric energy to the habitants of this town.
\end{abstract}

Key words: Capacity factor, Energy cost, Micro-Turbine, Wind energy potential, Wind power density, Wind speed

Cite this Article: Jose Galarza. Assessment of Wind Energy Potential and the Application for Micro-Turbines. International Journal of Electrical Engineering and Technology (IJEET). 12(9). 2021, pp. 20-31.

https://iaeme.com/Home/issue/IJEET?Volume $=12 \&$ Issue $=9$

\section{INTRODUCTION}

The increase in the use of renewable energies worldwide has allowed a wide use of wind and solar energy. In the case of South America, renewables for 2020 have increased by $4 \%$ over the previous year [1]. Distributed generation has allowed greater use of these technologies, wind micro-turbines are a source of generation for micro-grids, they can work freely or in 
coordination with the regional grid, the most important advantage of local generation is the reduction of transmission losses and increase the reliability and stability of the grid [2.3].

The energy production in a wind system basically depends on the wind speed, which has a dynamic nature and can be expressed in terms of probability of occurrence by the WD [4], in this context, for the estimation of wind energy potential, the use of WD has been extended as a necessary tool of analysis [5]. Wind modeling has been studied through different types of probability distribution, basically the WD and Rayleigh distribution [6], however, the different wind studies carried out establish that the WD reflects more accurately the stochastic nature of the wind [7,8], and it is also established that the Rayleigh distribution is a particular case of WD with a form factor equal to 2 [9].

\begin{tabular}{|c|c|}
\hline \multicolumn{2}{|r|}{ Nomeclature } \\
\hline $\mathrm{E}_{\mathrm{a}}$ & Mean annual energy (MWh). \\
\hline $\mathrm{E}_{\mathrm{a}}$ & Annual energy (MWh). \\
\hline $\mathrm{E}_{\mathrm{c}}$ & Energy cost (\$/MWh). \\
\hline$P_{i, w}$ & Parameter calculated by Weibull distribution. \\
\hline $\mathrm{P}_{\mathrm{i}, \mathrm{m}}$ & Parameter calculated by wind measures. \\
\hline$P_{e}$ & Power generated $(\mathrm{kW})$. \\
\hline $\mathrm{P}_{\mathrm{er}}$ & Rated power $(\mathrm{kW})$. \\
\hline $\mathrm{R}_{\mathrm{d}}$ & Rotor diameter $(\mathrm{m})$. \\
\hline $\mathrm{v}$ & Mean speed $(\mathrm{m} / \mathrm{s})$ \\
\hline $\mathrm{v}_{\mathrm{M}}$ & Wind speed for max. energy extraction $(\mathrm{m} / \mathrm{s})$. \\
\hline $\mathrm{v}_{\mathrm{C}}$ & Minimum speed (m/s). \\
\hline$v_{f}$ & Maximum speed $(\mathrm{m} / \mathrm{s})$. \\
\hline $\mathrm{v}_{\mathrm{m}}$ & Annual mean speed $(\mathrm{m} / \mathrm{s})$. \\
\hline $\mathrm{v}_{\mathrm{p}}$ & Most probable wind speed $(\mathrm{m} / \mathrm{s})$. \\
\hline $\mathrm{V}_{\mathrm{r}}$ & Rated speed $(\mathrm{m} / \mathrm{s})$. \\
\hline SENAMHI & National Meteorological and Hydrological Service of Peru \\
\hline $\mathrm{CF}$ & Capacity factor. \\
\hline EMJ & Empirical method of Justus. \\
\hline EML & Empirical method of Lysen. \\
\hline EPF & Energy pattern factor method. \\
\hline GP & Graphical method. \\
\hline I & Total cost (\$/MWh). \\
\hline ML & Maximum likelihood method. \\
\hline PVC & Present value of cost (\$). \\
\hline RRMSE & Relative root mean square error $(\%)$. \\
\hline WD & Weibull distribution. \\
\hline $\mathrm{WPD}_{\mathrm{m}, \mathrm{w}}$ & Wind power density $(\mathrm{W} / \mathrm{m} 2)$. \\
\hline c & Scale factor $(\mathrm{m} / \mathrm{s})$ \\
\hline $\mathrm{k}$ & Shape factor. \\
\hline $\mathrm{m}$ & Operating and maintenance cost $(\%)$. \\
\hline $\mathrm{n}$ & Number of measures. \\
\hline
\end{tabular}

In [10] several methods that estimate the WD parameters have been analyzed; the correction of the speed at different altitudes allows estimating more accurate results even with other wind potential estimation methods [11]. In [12] a comparative analysis of different methods to calculate $k$ and $c$ has been carried out, the results show that the ML, EMJ and EML methods allow estimating the WPD with accuracy, with a RRMSE less than 10\%. The analysis of WD parameters and the economic analysis considering the costs of a turbine have been performed in [9]. The estimated WPD values of $310 \mathrm{~W} / \mathrm{m}^{2}$ with a wind speed of $6.7 \mathrm{~m} / \mathrm{s}$ and the CF analysis allowed concluding the feasibility to install a small generation system or a wind farm. In [13] a comparison of methods to determine the WD parameters has been performed considering the equivalent energy method available in Wind Energy Industry-Standard software, the results 
show that moments method shows the best results, however, it is necessary to mention that the wind measurements correspond to a shape parameter value of 2.6, i.e. an instantaneous wind variation very close to the mean wind speed [10].

In [14-20] the wind potential has also been studied by WD, CF and WPD. The evaluation of commercial turbines allowed determining a comparative analysis in terms of $\mathrm{CF}$, however, the studies have only considered studies with medium and large power turbines, with the objective of installing a wind farm. The WD parameters have allowed direct estimation of the $\mathrm{CF}$, depending on the approximation of the power curve, the error can be substantial; the general power curve has allowed obtaining more accurate results $[4,19]$.

In this research, the wind power potential in the town of Junín (Peru) has been evaluated by estimating the wind energy potential with the meteorological information available in situ through the WD. The estimation of the CF considering commercial micro-turbines and energy cost has allowed choosing the best available option for this location.

This paper is organized as follows. Section 2 presents the methodology, indicating the meteorological station used, the theory used on WD and the evaluation of the wind system performance. Section 3 presents the results and discussion of the results, grouping the evaluation of wind power and energy cost using small commercial micro-turbines. Section 4 presents the conclusion of this work.

\section{METHODOLOGY}

\subsection{Meteorological Station and Location of Study}

The SENAMHI has installed various equipment throughout Peru to record hydrometeorological data, including meteorological stations that record wind speed. Table 1 shows information on the location of the meteorological station used in this research. SENAMHI on its website during 2018 has reported the wind speed information from 2012 to 2017 for the meteorological station in Junín.

Table 1 Data from Meteorological Station-Junin.

\begin{tabular}{|l|l|}
\hline \multicolumn{1}{|c|}{ Feature } & \multicolumn{1}{c|}{ Description } \\
\hline Name & Junín \\
\hline Type & Conventional-Meteorological \\
\hline Latitude (S) & $11^{\circ} 11^{\prime} 08^{\prime \prime}$ \\
\hline Longitude (W) & $75^{\circ} 59^{\prime 2} 20^{\prime \prime}$ \\
\hline Altitude & 4120 m.a.s.l. \\
\hline Location & Province of Junín (Junín-Peru) \\
\hline
\end{tabular}

The studies conducted in [12] allowed a general analysis of the wind potential in various locations using measurements from meteorological stations, this has allowed choosing the Junín as a site with wind potential that so far has not been exploited. Junín is a rural town, a sector of the city is dedicated to agricultural activities, several families do not have electricity services because the cost of investments in these rural areas is not feasible for the distribution utilities.

\subsection{Weibull Distribution}

The WD has been widely used in modeling wind performance characteristics [9-11,13-21]. The probability function $\mathrm{f}(\mathrm{v})$ and the cumulative probability function $\mathrm{F}(\mathrm{v})$ are expressed by $(1)$ and (2) according to [15].

$$
\begin{aligned}
& f(v)=\frac{k}{c}\left(\frac{v}{c}\right)^{k-1} \exp \left[-\left(\frac{v}{c}\right)^{k}\right] \\
& F(v)=1-\exp \left[-\left(\frac{v}{c}\right)^{k}\right]
\end{aligned}
$$


The scientific literature presents several methods to estimate the values of the $k$ and $c$ factors of the WD [12-15,17,20]. The EML method is the most appropriate to determine the Weibull parameters for the wind distribution of Junín [12], this method is expressed according to (3) and (4) in agreement with $[18,21,22]$.

$$
\begin{aligned}
& k=\left(\frac{\sigma}{\bar{v}}\right)^{-1.086} \\
& c=\bar{v}\left(0.568+\frac{0.4333}{k}\right)^{-\frac{1}{k}}
\end{aligned}
$$

Wind behavior can also be defined as a part of the WD. In [23] the calculation necessary to determine the velocities that characterize the wind behavior as a function of the Weibull parameters according to (5) and (6) is presented.

In [23] the calculation required to determine the speeds that characterize the wind performance as a function of the Weibull is presented, the most probable wind speed is shown in (5) and the wind speed for maximum energy is shown in (6).

$$
\begin{aligned}
& v_{p}=c\left(\frac{k-1}{k}\right)^{\frac{1}{k}} \\
& v_{M}=c\left(\frac{k+2}{k}\right)^{\frac{1}{k}}
\end{aligned}
$$

The WPD has vital importance for assessing the energy potential of a site and determining the feasibility of a site to install wind generation systems, WPD can be estimated using the Weibull parameters [18]. According to [13,19] the WPD is performed using expressions (7) and (8).

$$
\begin{aligned}
& W P D=\frac{1}{2} \rho v^{3} \\
& W P D=\frac{1}{2} \rho c^{3} \Gamma\left(1+\frac{3}{k}\right)
\end{aligned}
$$

The accuracy of the different methods to estimate the Weibull Distribution parameters were evaluated through the calculation of the WPD. In [12] a comparison of the accuracy of different methods and statistical indicators for the Junín station was carried out. The accuracy of the MLE method is evaluated by the RRMSE according to [18], this statistical indicator is presented in (9).

$$
R R M S E=\frac{\sqrt{\frac{1}{n} \sum_{i=1}^{n}\left(P_{i, w}-P_{i, m}\right)^{2}}}{\frac{1}{n} \sum_{i=1}^{n} P_{i, m}} x 100
$$

\subsection{Performance of the Micro-Turbine}

The CF represents an indicator of wind system efficiency, as it is expressed as a fraction: system power in a period over the nominal power. The expressions (10) and (11) allow the estimation of $\mathrm{CF}$ as a function of the Weibull parameters and the speed characteristics of the micro-turbine under analysis, (11) represents the analysis using the general wind power curve of a microturbine $[13,19]$.

$$
\begin{aligned}
& C F=\frac{P_{e}}{P_{e r}} \\
& P_{e}=P_{e r}\left[\frac{e^{-\left(\frac{V_{c}}{c}\right)^{k}-e^{-\left(\frac{V_{r}}{c}\right)^{k}}}}{\left(\frac{V_{r}}{c}\right)^{k}-\left(\frac{V_{c}}{c}\right)^{k}}-e^{-\left(\frac{V_{f}}{c}\right)^{k}}\right]
\end{aligned}
$$

The economic analysis of the wind micro-system allows considering the direct and indirect costs of the equipment, depending on the lifetime of the device and the interest rate the PVC has been determined in (12) according to [9]. 


$$
P V C=\frac{I}{t}\left(1+m \frac{(1+i)^{t}-1}{i(1+i)^{t}}\right)
$$

\section{RESULTS}

In the present investigation, the wind speed information provided by SENAMHI was used. These measures correspond to the Junín meteorological station, from 2012 to 2017 with a daily measurement interval. The information for 2020 is not currently available, however, the historical information for 6 years can be very well exploited, as is the case in the present research.

\subsection{Wind Energy Potential}

The work done in [12] shows a statistical analysis to estimate the parameters of the WD for wind measurements in Junín. Table 2 shows a comparison of the accuracy of the results of different methods to estimate the WPD. The results of the RRMSE show that the EML method presents a better estimation for $k$ and $c$, the error obtained indicates an estimation model with excellent accuracy because it is less than $10 \%$ [18].

Table 2 Accuracy of methods to estimate wind power density [12].

\begin{tabular}{|l|l|l|}
\hline \multicolumn{1}{|c|}{ Method } & RRMSE (\%) & \multicolumn{1}{c|}{ Rating } \\
\hline GP & 10.991 & Good \\
\hline EMJ & 8.400 & Excellent \\
\hline EML & 8.218 & Excellent \\
\hline EPF & 29.506 & Fair \\
\hline ML & 8.223 & Excellent \\
\hline
\end{tabular}

The accuracy of the EML method allowed to perform an annual analysis of the Weibull distribution parameters. The shape factor illustrates the peak of the wind distribution [18], the value obtained is between 3.2 to 4.2 , these values are in the interval of shape parameter according to [24], the value obtained allows to conclude that there is a non-uniform wind level. In the case of scale factor, which indicates the wind level at a given site [18], the value obtained is between 8.1 and 9.6, which indicates that the wind level is relatively high. The Table 3 shows the results of speeds, the values of $v_{p}$ and $v_{M}$ confirm the results obtained from the scale factor, the wind speeds recorded during 2012-2017 have a high site class according to IEC 61400.

Table 3 Wind speed from the Weibull distribution.

\begin{tabular}{|c|c|c|c|c|}
\hline Year & $\mathbf{k}$ & $\mathbf{c}$ & $\mathbf{v}_{\mathbf{p}}$ & $\mathbf{v} \mathbf{M}$ \\
\hline 2012 & 3.5805 & 9.6445 & 8.8014 & 10.9171 \\
\hline 2013 & 3.8716 & 9.1230 & 8.4454 & 10.1591 \\
\hline 2014 & 4.1788 & 8.9894 & 8.4198 & 9.8713 \\
\hline 2015 & 4.2004 & 8.7517 & 8.2031 & 9.6019 \\
\hline 2016 & 3.7970 & 8.5604 & 7.8983 & 9.5695 \\
\hline 2017 & 3.2326 & 8.1186 & 7.2403 & 9.4229 \\
\hline
\end{tabular}

The histogram in Fig. 1a shows for 2012 a non-uniform distribution of winds, the predominant winds are in the range of $8-12 \mathrm{~m} / \mathrm{s}$, the value of $\mathrm{v}_{\mathrm{p}}$ corresponds to the maximum value of the WD, confirming a similar behavior for the years 2013-2016 in Fig. 1b,2a,2b, and 3a. For the case of 2017 in Fig. $3 b$ a distribution of winds is evidenced with a higher value of the histogram for the values of 4-6 m/s and 6-12 m/s, consequently, it presents the lowest value of the scale factor. 

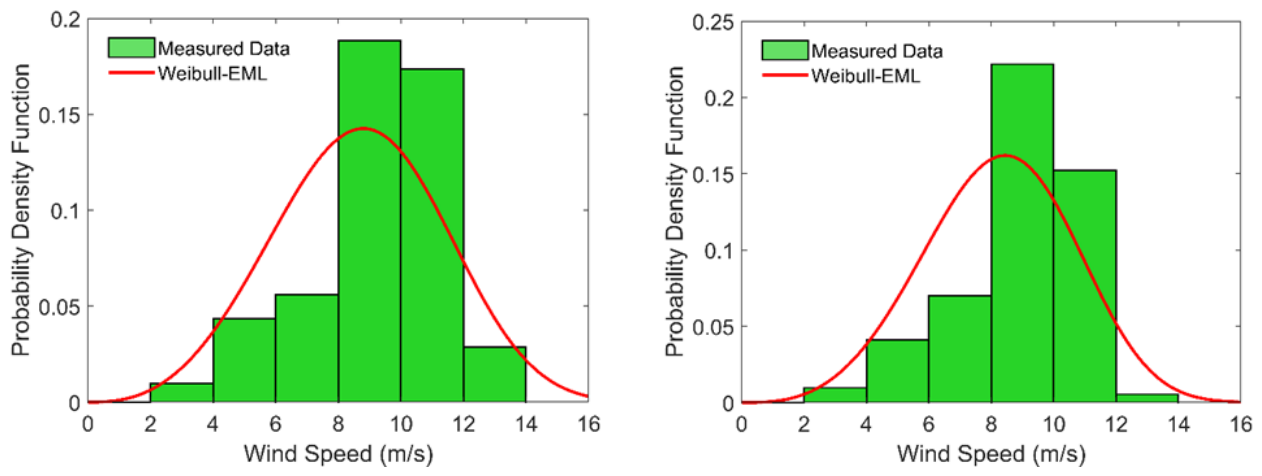

Figure 1 Probability Density Function and Histogram (a) year 2012; (b) year 2013
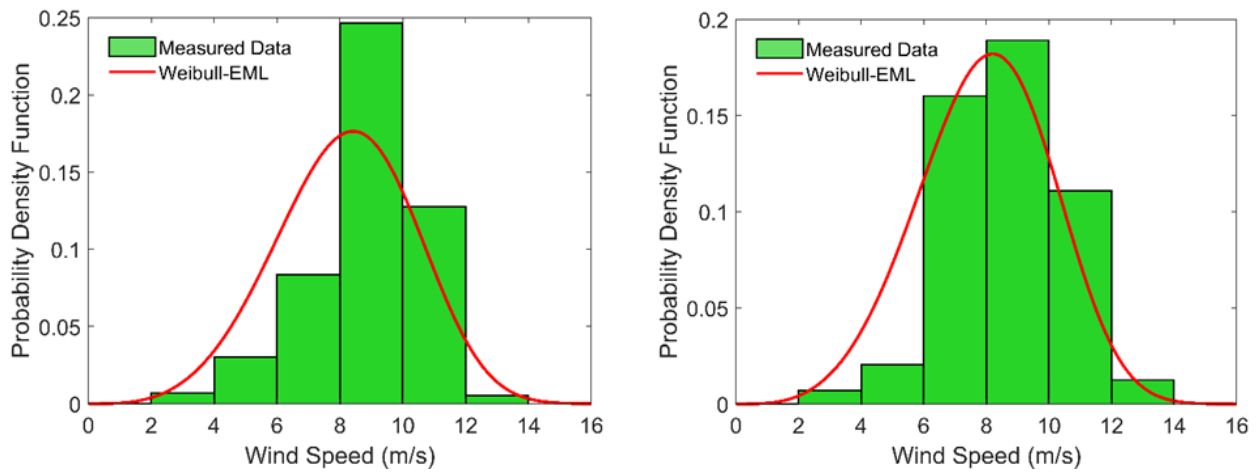

Figure 2 Probability Density Function and Histogram (a) year 2014; (b) year 2015
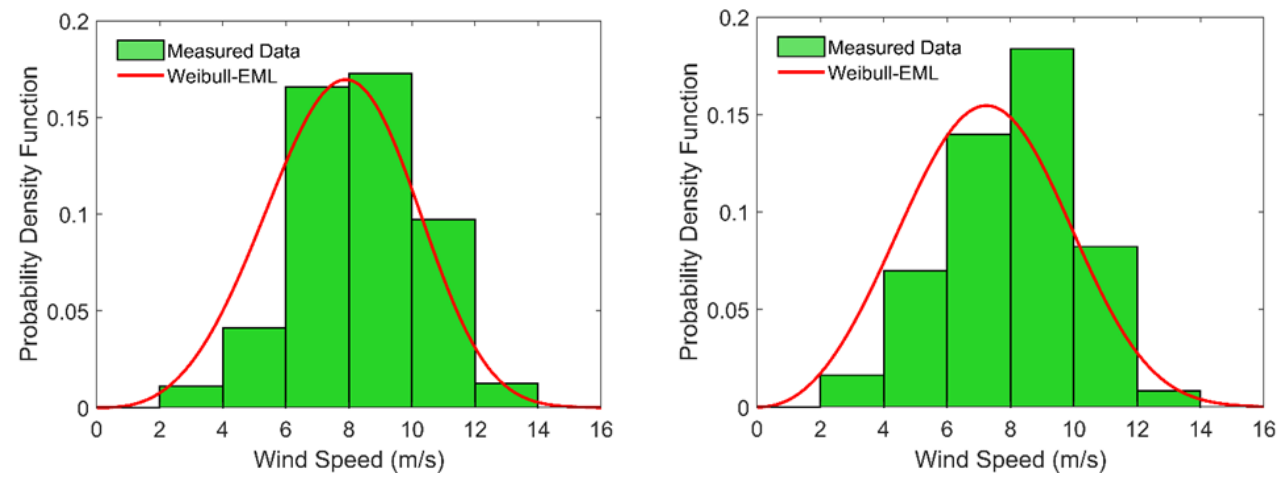

Figure 3 Probability Density Function and Histogram (a) year 2016; (b) year 2017

Using the EML method, the WPD for each year has been determined, Table 4 shows the results. The WPD values achieved suggest that Junín has a considerably high energy potential compared to other places, as is the case of Kiribati where a maximum value of $139 \mathrm{~W} / \mathrm{m}^{2}$ was found for a height of $34 \mathrm{~m}$ [13]; in places such as Babaurband (Pakistan), values of $137.5 \mathrm{~W} / \mathrm{m}^{2}$ for a height of $10 \mathrm{~m}$ have been determined [9]. Depending on the area of the turbine to be used, a better use of the wind conditions will be realized, in [13], evidently turbines with radius greater than $30 \mathrm{~m}$ have been used, consequently a higher energy production is expected.

Unlike other studies mentioned above, where the use of wind turbines in the order of $\mathrm{kW}$ is established, this work is focused on the use of micro-turbines. In the town of Junín, the conditions for the installation of small equipment in rural areas are established, excluding the use of energy as a wind farm. 
Table 4 Wind power density from the Weibull distribution.

\begin{tabular}{|c|c|c|}
\hline Year & WPD $_{\mathbf{m}}$ & WPD $_{\mathbf{w}}$ \\
\hline 2012 & 514.2004 & 517.5884 \\
\hline 2013 & 427.5418 & 430.1715 \\
\hline 2014 & 405.3290 & 405.8495 \\
\hline 2015 & 375.6169 & 374.1953 \\
\hline 2016 & 359.1213 & 356.8690 \\
\hline 2017 & 319.3793 & 318.4704 \\
\hline
\end{tabular}

\subsection{Application for Micro-Turbine}

\subsubsection{Micro-Turbine and Energy Cost}

The promising results obtained in the previous section made it possible to develop an analysis considering different commercially micro-turbines. In the case of the Junín, the objective is to take advantage of the wind potential of the area to cover the demand of the rural town, as well as to improve their living conditions, in this context, the evaluation has been arranged with micro-turbines with a rotor radius of a maximum value of $2.5 \mathrm{~m}$, since they are structures that will be installed on the houses or very close to them.

The economic part has been evaluated by the annual energy cost considering a useful lifetime of the micro-turbine of 20 years, an interest rate of $10 \%$ and the operation and maintenance costs of $30 \%$. The results in Table 5 shows for Zonhan ZH1KW and Zonhan ZH500W an equal value of \$/MWh, however, depending on the number of turbines to be used and their location in the area, one or the other option can be chosen. In the group of options evaluated, both micro-turbines have the lowest energy cost, a nominal speed that is very close to most probable wind speed, thus presenting a technically and economically suitable option.

The comparison of the various micro-turbines is related to the objective of achieving the highest energy production at the lowest price. Fig. 4 shows the relationship between cost and energy produced, with a double arrow indicating this relationship with normalized values; the best option is expected to be obtained with a ratio much larger than 1 .

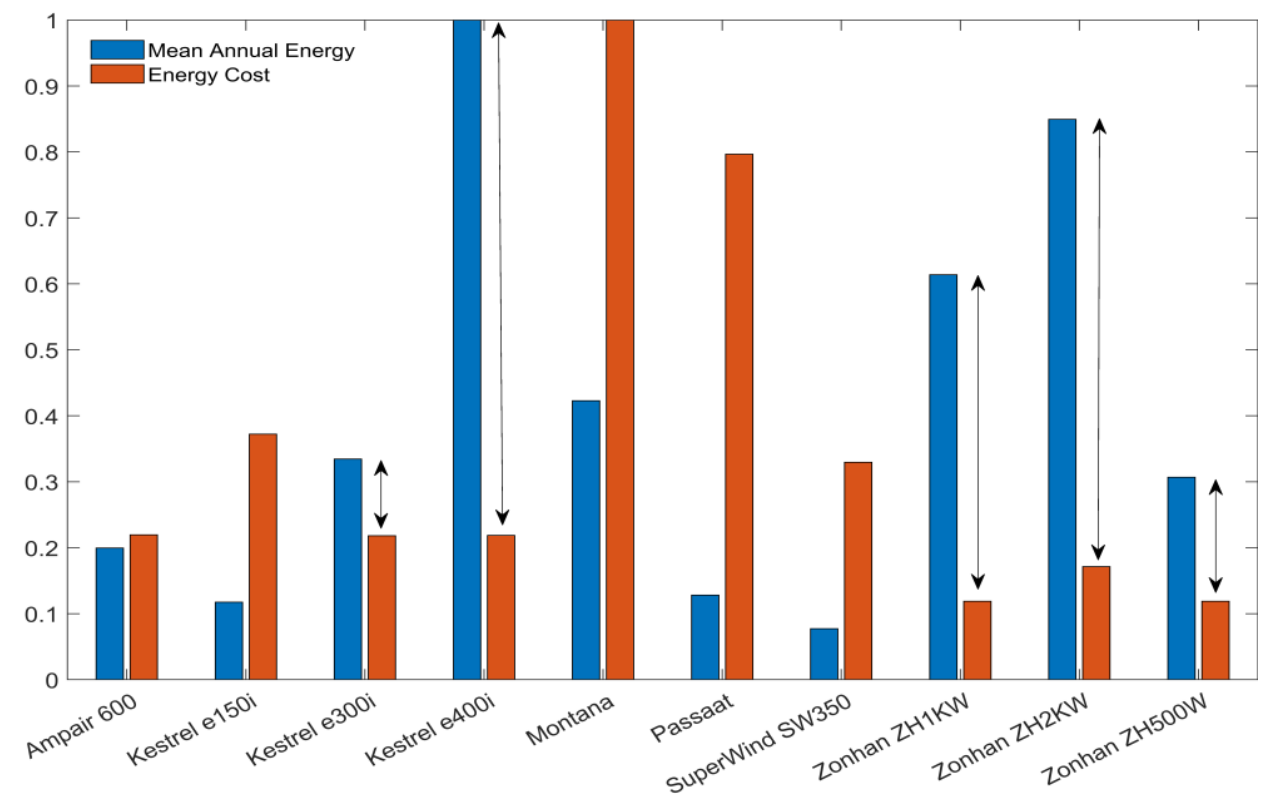

Figure 4 Comparison with normalized values: mean annual energy and energy cost of micro turbines. 
For the Zonhan ZH1KW micro-turbine a ratio of 5.1579 is established, being considered a feasible economic option, the highest production at the lowest price. For the Zonhan ZH2KW the ratio is 4.9538 , Kestrel e400 has 4.5702 , Zonhan ZH500W has 2.579 and finally Kestrel e300i has 1.5327. All these turbines can be considered as an option to be implemented because they have an indicator above the threshold.

\subsubsection{Wind Speed and Energy Cost}

The WD allows estimating the average and most probable velocities based on the probability function established by the Weibull parameters. Considering the speed parameters of Table 3 , the Fig. 5 shows the comparative of micro-turbines analyzing the cost and the physical dimensions (rotor radius) that will allow a certain amount of energy. Fig. 5 allows to establish the lowest cost requirement and nominal speed close to the most probable speed; the results show that both Zonhan ZH1 KW and Zonhan ZH500W turbines are the best options. In the case of Zonhan $\mathrm{ZH} 2 \mathrm{KW}$ it has a higher energy cost; however, it has a rated speed very close to the average speed; based on this consideration it is also an option to be considered.

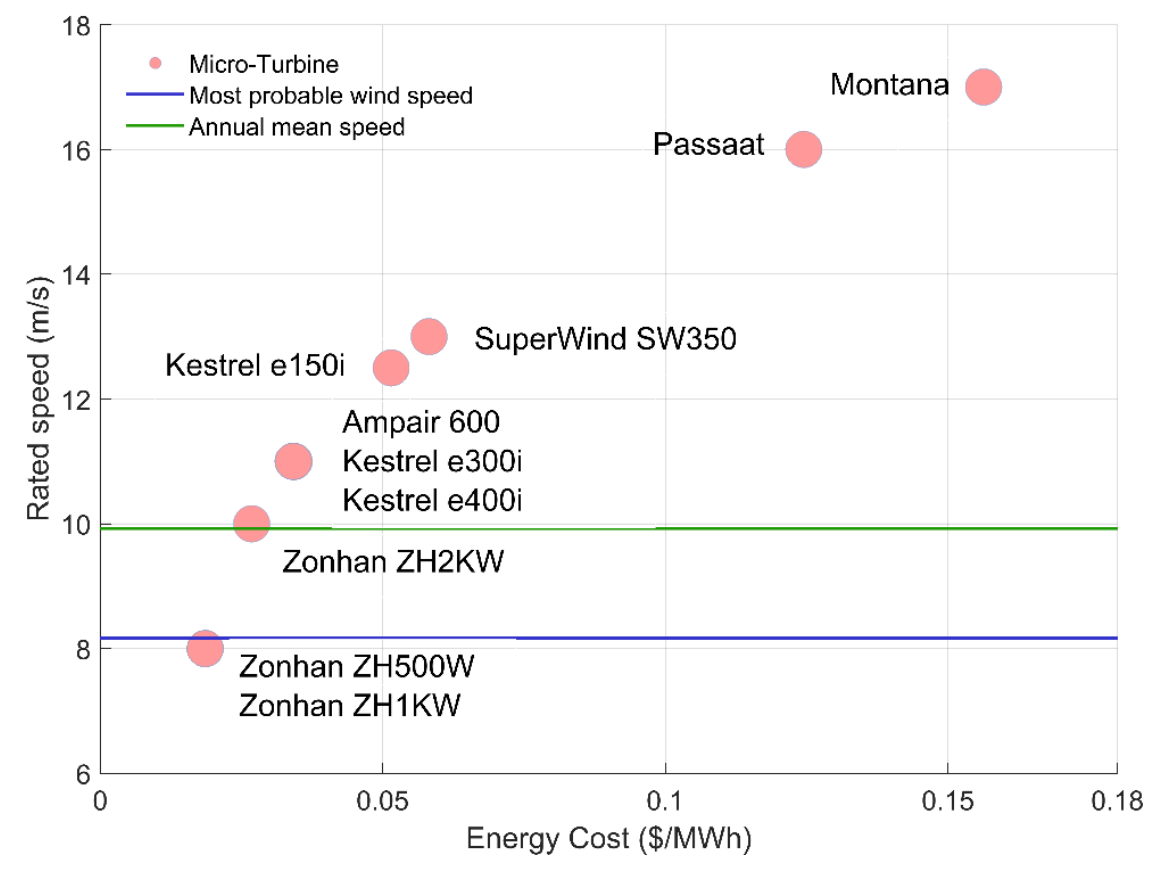

Figure 5 Relationship between rated speed and energy cost for micro-turbine

The other micro-turbines present a nominal speed above the wind regimes for the area under study, in some cases, such as Passat and Montana, they present costs up to 3 times greater than the lower cost turbine, therefore, they cannot be considered as a valid option.

\subsubsection{Wind Power Density and Energy Cost}

With the information in Table 4, the average WPD is $400.524 \mathrm{~W} / \mathrm{m}^{2}$, this result allows estimating the energy that each turbine will be able to produce, directly proportional to the rotor area. The average electricity consumption in rural areas of Peru is $30 \mathrm{kWh}$ per month, using this information Fig. 9 has been elaborated to determine approximately the number of families that could be supplied from each micro-turbine. The results of Fig. 6 show that considering the criteria of lowest energy cost and highest energy production, the Zonhan ZH500W, Zonhan $\mathrm{ZH} 1 \mathrm{KW}$ and Zonhan ZH2KW micro-turbines present the best option, making it possible to ideally supply the consumption of between 12 to 19 families in the rural area. The SuperWind350, Kestrel e150i and Ampair 600 micro-turbines have a lower energy production and a higher price, being able to supply between 3 to 5 families. For the Kestrel e300i and 
Kestrel e400i micro-turbines, the estimated cost is double that of the best option turbines, however, it is also possible to supply up to twice as many consumers, between 17 to 30 families. The case of the Passat micro turbine clearly shows that it is not a suitable option compared to Kestrel e300i or Zohan ZH2KW; it can supply a similar number of families, but Passat presents a cost that is too high compared to both turbines.

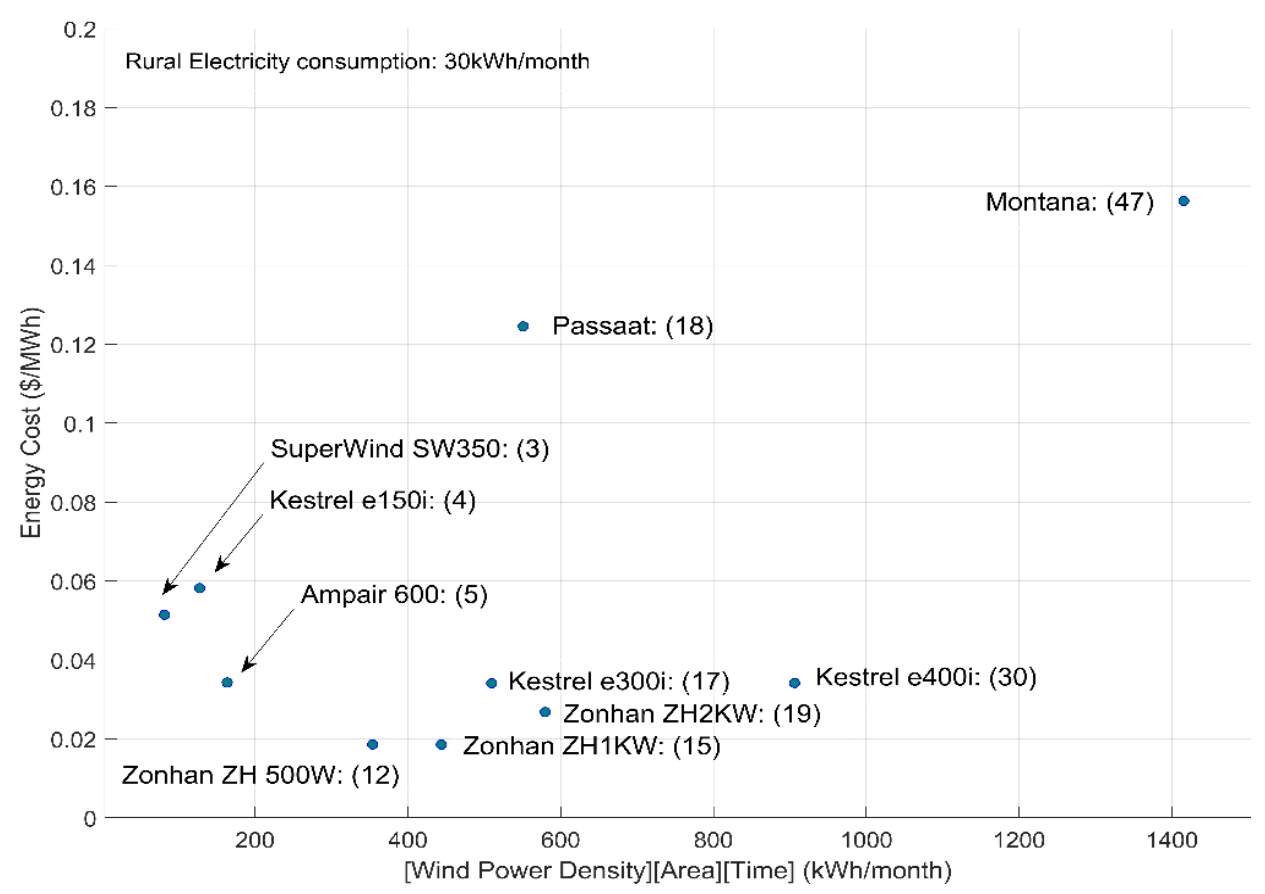

Figure 6 Balance between rural electricity consumption, energy costs and production per month

The case of the Montana micro-turbine could supply 47 families, but compared to the Zohan $\mathrm{ZH} 500 \mathrm{~W}$ it has an energy cost 8 times higher, so it would be more convenient to use a larger number of Zohan ZH 500W micro-turbines to supply a larger number of families.

\subsubsection{Capacity Factor}

The efficiency of the microturbine has been determined through the CF with respect to the technical analysis. Table 5 shows a comparison between 10 micro-turbines, for the dimensions of the tower height, rotor diameter and size these devices can be installed in houses without difficulties. For the Zonhan ZH1KW and Zonhan ZH500W micro-turbines, a CF of $72.07 \%$ has been estimated; for certain equipment such as Montana and Passat, values of less than 10\% have been determined. As shown in Fig. 6, Montana and Passat have the capacity to supply a larger number of families, however, with the wind conditions of the Junín region, the total generation capacity of the micro-turbine is not used; due to this, a low CF value has been obtained, associated to oversizing and nominal speed values much higher than those required.

The CF could be higher if the average speeds were higher or if the turbines were installed at a higher elevation [13]. In the present investigation it has been determined that the Zonhan ZH1KW and Zonhan ZH500W micro-turbines present an advantage over the others because of their high CF value, the nominal speeds of $8 \mathrm{~m} / \mathrm{s}$ is very close to the values of $v_{p}$ and scale factor, the high CF values are in line with the supporting statements in [4] where it has been established that the $\mathrm{CF}$ is high due to the fact that the mean velocity is very close to the nominal velocity. 
Table 5 Comparison of efficiency, energy production and energy cost.

\begin{tabular}{|l|c|c|c|c|c|}
\hline \multicolumn{1}{|c|}{ Turbine } & $\mathbf{v}_{\mathbf{r}}$ & $\mathbf{R d}$ & $\mathbf{C F}$ & $\mathbf{E}_{\mathbf{a}}$ & $\mathbf{E}_{\mathbf{c}}$ \\
\hline $\begin{array}{l}\text { SuperWind } \\
\text { SW350 }\end{array}$ & 12.5 & 1.2 & 0.2597 & 0.7961 & 0.0515 \\
\hline Zonhan ZH500W & 8 & 2.5 & 0.7207 & 3.1565 & 0.0186 \\
\hline Ampair 600 & 11 & 1.7 & 0.3903 & 2.0515 & 0.0343 \\
\hline Kestrel e150i & 13 & 1.5 & 0.2298 & 1.2076 & 0.0582 \\
\hline Kestrel e300i & 11 & 3 & 0.3926 & 3.4391 & 0.0341 \\
\hline Zonhan ZH1KW & 8 & 2.8 & 0.7207 & 6.3129 & 0.0186 \\
\hline Passaat & 16 & 3.12 & 0.1075 & 1.3179 & 0.1245 \\
\hline Zonhan ZH2KW & 10 & 3.2 & 0.4986 & 8.7361 & 0.0268 \\
\hline Kestrel e400i & 11 & 4 & 0.3914 & 10.2850 & 0.0342 \\
\hline Montana & 17 & 5 & 0.0856 & 4.3485 & 0.1563 \\
\hline
\end{tabular}

Table 6 shows a summary by year of the CF and energy assessment for the Zonhan ZH500W $0.5 \mathrm{~kW}$ micro-turbine. Evaluating the worst-case scenario conditions corresponding to 2017 where WPD is $328.5 \mathrm{~W} / \mathrm{m}^{2}$, a CF value of $63.64 \%$ and $\mathrm{E}_{\mathrm{a}}$ of $2.78 \mathrm{MWh}$ has been obtained, these results are still promising for installing wind generation systems in that location $[4,13]$. In contrast to other works mentioned above, in the present work, microturbines have been chosen especially with a nominal speed close to the speed with the highest probability of occurrence according to WD calculations.

Table 6 Wind energy potential for micro-turbine Zonhan ZH500W.

\begin{tabular}{|c|c|c|c|}
\hline Year & $\mathbf{C F}$ & $\mathbf{P}_{\mathbf{g}}$ & $\mathbf{E}_{\mathbf{a}}$ \\
\hline 2012 & 0.7792 & 0.3896 & 3.4131 \\
\hline 2013 & 0.7488 & 0.3744 & 3.2796 \\
\hline 2014 & 0.7452 & 0.3726 & 3.2640 \\
\hline 2015 & 0.7216 & 0.3608 & 3.1607 \\
\hline 2016 & 0.6927 & 0.3464 & 3.0341 \\
\hline 2017 & 0.6364 & 0.3182 & 2.7873 \\
\hline
\end{tabular}

\section{CONCLUSION}

The evaluation of the energy potential in the town of Junín has been evaluated by Weibull distribution through in situ experimental measurements. Through the Empirical method of Lysen, the wind power density has been accurately estimated to evaluate the wind energy potential, resulting in a range of $318.5-517.6 \mathrm{~W} / \mathrm{m}^{2}$. The results of the energy production, capacity factor, energy costs and rural application using commercially micro-turbines have allowed establishing that the Zonhan ZH1KW $(1 \mathrm{~kW})$ and Zonhan ZH500W $(0.5 \mathrm{~kW})$ are the best micro-turbines options for the Junín rural town with an efficiency level of $72 \%$ and an average annual production of 3.16 and 6.31 MWh respectively. This option has been considered taking into various micro-turbine options available in the market, which can be easily installed in rural areas due to their small size (rotor diameter and tower height). It is expected that the use of microturbines with a maximum radius of $2.5 \mathrm{~m}$ will satisfy the local energy demand, taking advantage of the available wind resource and making the least modification to the households that can benefit from this renewable energy source.

\section{ACKNOWLEDGEMENT}

The author thanks the National University of the Center of Peru (UNCP) and the Department of Electrical and Electronic Engineering for the technical facilities used for the development of this research. 


\section{Jose Galarza}

\section{REFERENCES}

[1] Irena, A. (2020). Renewable capacity highlights. In Proc. Int. Renew. Energy Agency (IRENA) (pp. 1-8).

[2] Car, M., Vašak, M., \& Lešić, V. (2017). Control of a buck-boost DC-DC power converter for microgrid energy storage. In 2017 19th International Conference on Electrical Drives and Power Electronics (EDPE) (pp. 122-127).

[3] El-Shahat, A., \& Sumaiya, S. (2019). DC-Microgrid System Design, Control, and Analysis. Electronics, 8(2), 124.

[4] Walia, S., \& Sandhu, K. S. (2019). Capacity factor of wind turbine system based on different power curves and Weibull distribution parameters. In 2019 3rd International Conference on Computing Methodologies and Communication (ICCMC) (pp. 1135-1138).

[5] Azad, A. K., Rasul, M. G., \& Yusaf, T. (2014). Statistical diagnosis of the best weibull methods for wind power assessment for agricultural applications. Energies, 7(5), 3056-3085.

[6] Ali, S., Lee, S.-M., \& Jang, C.-M. (2018). Statistical analysis of wind characteristics using Weibull and Rayleigh distributions in Deokjeok-do Island--Incheon, South Korea. Renewable Energy, 123, 652-663.

[7] Georgiev, A., \& Sulakov, S. (2019). Modelling of hourly wind generation using pan-European climatic data base and Weibull probability distribution. In 2019 16th International Conference on the European Energy Market (EEM) (pp. 1-4).

[8] Nayak, A. K., \& Mohanty, K. B. (2017). Adequacy assessment of wind energy conversion system through simulating wind speed using weibull distribution. In 2017 National Power Electronics Conference (NPEC) (pp. 102-105).

[9] Khahro, S. F., Tabbassum, K., Soomro, A. M., Dong, L., \& Liao, X. (2014). Evaluation of wind power production prospective and Weibull parameter estimation methods for Babaurband, Sindh Pakistan. Energy Conversion and Management, 78, 956-967.

[10] Katinas, V., Marčiukaitis, M., Gecevičius, G., \& Markevičius, A. (2017). Statistical analysis of wind characteristics based on Weibull methods for estimation of power generation in Lithuania. Renewable Energy, 113, 190-201.

[11] Jung, C., \& Schindler, D. (2017). Development of a statistical bivariate wind speed-wind shear model (WSWS) to quantify the height-dependent wind resource. Energy Conversion and Management, 149, 303-317.

[12] Galarza, J., Condezo, D., Camayo, B., Mucha, E., \& others. (2019). Assessment of wind power density based on weibull distribution in region of junin, peru. Energy and Power Engineering, 12(01), 16

[13] Aukitino, T., Khan, M. G. M., \& Ahmed, M. R. (2017). Wind energy resource assessment for Kiribati with a comparison of different methods of determining Weibull parameters. Energy Conversion and Management, 151, 641-660.

[14] Ahmed, S. A. (2013). Comparative study of four methods for estimating Weibull parameters for Halabja, Iraq. International Journal of Physical Sciences, 8(5), 186-192.

[15] Altmimi, A., \& Ceekhan, A. (2017). Calculate and compare five of Weibull distribution parameters to estimate wind power in Iraq. In 2017 8th International Renewable Energy Congress (IREC) (pp. 1-5).

[16] de Araujo Lima, L., \& Bezerra Filho, C. R. (2010). Wind energy assessment and wind farm simulation in Triunfo--Pernambuco, Brazil. Renewable Energy, 35(12), 2705-2713.

[17] Chang, T. P. (2011). Performance comparison of six numerical methods in estimating Weibull parameters for wind energy application. Applied Energy, 88(1), 272-282. 
[18] Mohammadi, K., Alavi, O., Mostafaeipour, A., Goudarzi, N., \& Jalilvand, M. (2016). Assessing different parameters estimation methods of Weibull distribution to compute wind power density. Energy Conversion and Management, 108, 322-335.

[19] Ohunakin, O. S. (2011). Assessment of wind energy resources for electricity generation using WECS in North-Central region, Nigeria. Renewable and Sustainable Energy Reviews, 15(4), 1968-1976.

[20] Yuan, F. Q., Barabadi, A., Lu, J. M., \& Garmabaki, A. H. S. (2015). Performance evaluation for maximum likelihood and moment parameter estimation methods on classical two Weibull distribution. In 2015 IEEE International Conference on Industrial Engineering and Engineering Management (IEEM) (pp. 802-806).

[21] Mohammadi, K., \& Mostafaeipour, A. (2013). Using different methods for comprehensive study of wind turbine utilization in Zarrineh, Iran. Energy Conversion and Management, 65, 463-470.

[22] Lysen, E. H. (1983). Introduction to wind energy. Basic and advanced introduction to wind energy with emphasis on water pumping windmills.

[23] Chauhan, A., \& Saini, R. P. (2014). Statistical analysis of wind speed data using Weibull distribution parameters. In 2014 1st International Conference on Non Conventional Energy (ICONCE 2014) (pp. 160-163).

[24] Weisser, D. (2003). A wind energy analysis of Grenada: an estimation using the Weibull density function. Renewable Energy, 28(11), 1803-1812. 